\title{
Quantitative PCR for Etiologic Diagnosis of Methicillin-Resistant Staphylococcus aureus Pneumonia in Intensive Care Unit
}

\author{
Sun-Jung Kwon, M.D. ${ }^{1,2 \star}$, Taehyeon Jeon ${ }^{1 \star}$, Dongwook Seo ${ }^{1 *}$, Moonjoon Na, M.D., Ph.D. ${ }^{2}$, Eu-Gene Choi, \\ M.D., Ph.D. ${ }^{2}$, Ji-Woong Son, M.D., Ph.D. ${ }^{2}$, Eun-Hyung Yoo, M.D. ${ }^{3}$, Chang-Gyo Park, Ph.D. i ', Hoi Young Lee, \\ Ph.D. ${ }^{1}$, Ju Ock Kim, M.D., Ph.D. ${ }^{4}$, Sun-Young Kim, M.D., Ph.D. ${ }^{4}$, Jaeku Kang, Ph.D. ${ }^{1}$ \\ ${ }^{1}$ Myunggok Medical Research Institute, Konyang University College of Medicine, Departments of ${ }^{2}$ Internal Medicine and \\ ${ }^{3}$ Laboratory Medicine, Konyang University Hospital, Konyang University College of Medicine, ${ }^{4}$ Department of Internal Medicine, \\ Chungnam National University School of Medicine, Daejeon, Korea
}

\begin{abstract}
Background: Ventilator-associated pneumonia (VAP) requires prompt and appropriate treatment. Since methicillinresistant Staphylococcus aureus (MRSA) is a frequent pathogen in VAP, rapid identification of it, is pivotal. Our aim was to evaluate the utility of quantitative polymerase chain reaction (qPCR) as a useful method for etiologic diagnoses of MRSA pneumonia.

Methods: We performed qPCR for mecA, $S$. aureus-specific femA-SA, and $S$. epidermidis-specific femA-SE genes from bronchoalveolar lavage or bronchial washing samples obtained from clinically-suspected VAP. Molecular identification of MRSA was based on the presence of the mecA and femA-SA gene, with the absence of the femA-SE gene. To compensate for the experimental and clinical conditions, we spiked an internal control in the course of DNA extraction. We estimated number of colony-forming units per $\mathrm{mL}(\mathrm{CFU} / \mathrm{mL})$ of MRSA samples through a standard curve of a serially-diluted reference MRSA strain. We compared the threshold cycle (Ct) value with the microbiologic results of MRSA.

Results: We obtained the mecA gene standard curve, which showed the detection limit of the mecA gene to be $100 \mathrm{fg}$, which corresponds to a copy number of 30. We chose cut-off Ct values of 27.94 (equivalent to $1 \times 10^{4}$ $\mathrm{CFU} / \mathrm{mL}$ ) and 21.78 (equivalent to $1 \times 10^{5} \mathrm{CFU} / \mathrm{mL}$ ). The sensitivity and specificity of our assay were $88.9 \%$ and $88.9 \%$ respectively, when compared with quantitative cultures.

Conclusion: Our results were valuable for diagnosing and identifying pathogens involved in VAP. We believe our modified qPCR is an appropriate tool for the rapid diagnosis of clinical pathogens regarding patients in the intensive care unit.
\end{abstract}

Key Words: Methicillin-Resistant Staphylococcus aureus; Real-Time Polymerase Chain Reaction; Pneumonia, Ventilator-Associated

Address for correspondence: Jaeku Kang, Ph.D. Department of Pharmacology, Konyang University College of Medicine, 685, Gasuwon-dong, Seo-gu, Daejeon 302-718, Korea

Phone: 82-42-600-6415, Fax: 82-42-541-4626

E-mail: jaeku@konyang.ac.kr

Co-correspondence: Sun-Young Kim, M.D., Ph.D. Department of Internal Medicine, Chungnam National University School of Medicine, 640, Daesa-dong, Jung-gu, Daejeon 302-721, Korea

Phone: 82-42-280-7154, Fax: 82-42-257-5753

E-mail: sykim@cnu.ac.kr

"Sun-Jung Kwon, Taehyeon Jeon, and Dongwook Seo have contributed equally to this work.

Received: Dec. 16, 2011

Revised: Jan. 9, 2012

Accepted: Jan. 27, 2012

\section{Introduction}

Hospital-acquired pneumonia (HAP) is the second most common nosocomial infection ${ }^{1}$. HAP is $6 \sim 20$ times more common in mechanically-ventilated patient, and ventilator associated pneumonia (VAP) occurs in 9 $\sim 27 \%$ of all intubated patients ${ }^{2,3}$. The mortality rate of VAP has been reported to range between 33\% and $50 \%{ }^{4}$. Because of increasing mortality, most patients with pneumonia are treated with broad-spectrum antibiotics, and this treatment increases hospital cost as well as the prevalence of resistant strains ${ }^{5}$. To minimize the 
risk of mortality, clinicians are recommended to avoid delaying administration of appropriate antibiotic treatments ${ }^{6}$.

The National Nosocomial Infection Surveillance from 2003 found that Staphylococcus aureus was the most common pathogen associated with VAP (27.8\%) in US1. Methicillin resistance is caused by the penicillin-binding protein $2 \mathrm{a}$ (PBP2a), which is encoded by the methicillin-resistant Staphylococcus aureus (MRSA) mecA gene. Because genes for methicillin resistance in Staphylococcus aureus are well-known, mecA is used to differentiate between methicillin-sensitive Staphylococcus aureus (MSSA) and MRSA ${ }^{7}$.

Because the results of a microbiologic culture were not immediately available, empirical antibiotic therapy could lead to inadequate antibiotic treatment. Molecular-based diagnostic methods, such as quantitative polymerase chain reaction (qPCR), have been evaluated for their ability to identify MRSA by detecting the mecA gene $^{8-10}$. This has the potential to deliver rapid, specific and sensitive detection. Previously, a study with the qPCR of blood indentified sepsis-relevant microorganisms $^{11}$. Because qPCR for MRSA was limited to surveillance with nasal swabs, it was impossible to determine whether the specimens were true pathogens or colonization $^{12}$. Multiplex PCR to detect Gram negative bacilli could not discriminate true pathogens, previously ${ }^{13}$. qPCR have not been completely evaluated for their ability to provide etiologic diagnostic criteria for clinical specimens $^{14,15}$.

The object of this study was to develop and validate a qPCR assay from MRSA detection on bronchoalveolar lavage (BAL) or bronchial washing samples.

\section{Materials and Methods}

\section{Specimen preparation and extract clinical data}

This study was performed at a 52-bed intensive care unit (ICU) in Konyang University Hospital (Daejeon, Korea). Samples consisting of a BAL and bronchial washing samples were collected directly from patients admitted to the ICU. The study included 72 clinical sam- ples that consisted of 72 VAP episodes in 64 patients, during a period of 11 months (March 2010 to February 2011). The study was approved by the Institutional Review Board of Konyang University Hospital, and we received informed consent from all patients.

\section{BAL and bronchial washing samples}

We obtained clinical samples from patients who had "clinically-suspected pneumonia" that was defined as follows: patients received mechanical ventilation for at least 48 hours in the ICU and had new or progressive infiltration on chest X-rays. In addition, patients had at least two of following symptoms indicating infection: 1) temperature $<36^{\circ} \mathrm{C}$ or $\left.\geq 38.3^{\circ} \mathrm{C}, 2\right)$ white blood cell $<5,000$ cells $/ \mathrm{mm}^{3}$ or $>10,000$ cells $/ \mathrm{mm}^{3}$, and 3) purulent sputum ${ }^{4}$.

BAL samples were taken from pulmonary subsegments and bronchial washing samples were taken, using fiberoptic bronchoscopy from a segment or lobe in which new or progressive infiltration had developed. If lesions were not identified, samples were taken from basal segments of lower lobe. We performed the BAL procedure and bronchoscopy methods standard in the $\mathrm{ICU}^{16}$.

\section{Identification and antimicrobial susceptibility: breakpoint by Clinical and Laboratory Standards Institute guidelines}

Quantitative cultures of BAL or bronchial washing specimens were performed in a microbiology laboratory. The specimens were inoculated in blood and MacConkey agar plates with a $0.001 \mathrm{~mL}-$ loop. After incubation at $37^{\circ} \mathrm{C}$ in a $5 \% \mathrm{CO}_{2}$ incubator, for 24 hours, a colony count was performed and expressed as the number of colony-forming units per $\mathrm{mL}(\mathrm{CFU} / \mathrm{mL})$. In general, the number of $\mathrm{CFU} / \mathrm{mL}$ is equal to the number of colonies on the agar plate multiplied by the inoculation factor. In our quantitative culture, the pathogen was evaluated by the diagnostic criteria for BAL specimens $\left(\geq 1 \times 10^{4} \mathrm{CFU} / \mathrm{mL}\right)$ and bronchial washing specimens $\left(\geq 1 \times 10^{5} \mathrm{CFU} / \mathrm{mL}\right)$. Organisms isolated from specimens were confirmed using Combo Panels of 
the MicroScan WalkAway 96 system (Dade Behring, West Sacramento, CA, USA) for antimicrobial susceptibility and species identification.

\section{DNA extraction}

To extract DNA from BAL or bronchial washing samples, we used a NucleoSpin ${ }^{\circledR}$ Tissue extraction kit (MACHEREY-NAGEL, Neumann-Neander-Str., Germany), closely following the manufacture's protocols. The clinical sample volume was $1 \mathrm{~mL}$, and an equal volume of $\mathrm{N}$-acetyl $/ \mathrm{NaOH}$ was added to the sample. After incubating the mixture for 25 minutes at room temperature, while shaking it, the mixture volume was adjusted to $25 \mathrm{~mL}$ with sterile water and the mixture was centrifuged at 4,000 $\times \mathrm{g}$ for 30 minutes. The supernatant was discarded, two hundred $\mu \mathrm{L}$ of buffer T1 was used to re-suspend the pellet, and $25 \mu \mathrm{L}$ of proteinase $\mathrm{K}$ was added. For inhibitor control, 100 pg of spiked an internal control (SPUD) (Table 1) was also added. The samples were incubated at $56^{\circ} \mathrm{C}$ and were shaken until complete lysis was obtained. Two hundred $\mu \mathrm{L}$ of buffer B3 was added for lysis, and the sample was incubated at $70^{\circ} \mathrm{C}$ for 10 minutes. Then, $210 \mu \mathrm{L}$ of ethanol (96 100\%) was added, and the sample was placed on a NucleoSpin ${ }^{\circledR}$ tissue column, in a collection tube. After centrifugation for 1 minute at 11,000 $\times \mathrm{g}$, the flow-through was discarded, and $500 \mu \mathrm{L}$ of buffer BW were added for first wash. The sample was then centrifuged for 1 minute at 11,000 $\times \mathrm{g}$. Next, $600 \mu \mathrm{L}$ of buffer B5 were added to the column for the second wash and centrifuged for 1 minute at 11,000 ×g. The flow-through was the discarded, and the column was centrifuged for 1 minute at $11,000 \times \mathrm{g}$ in order to remove residual ethanol. Then, $50 \mu \mathrm{L}$ of pre-warmed elution buffer $\mathrm{BE}$ $\left(70^{\circ} \mathrm{C}\right)$ was added, and the sample was incubated at $25^{\circ} \mathrm{C}$ for 1 minute. After centrifugation for 1 minute at $11,000 \times \mathrm{g}$, the extracted DNA preparations were adjusted to a final volume of $50 \mu \mathrm{L}$.

\section{Reference strains}

Three reference strains of Staphylococcus spp., including methicillin-resistant and, methicillin-susceptible strains, were included in the study. The strains were MRSA (ATCC 33591), MSSA (ATCC 25923), and methicillin-sensitive Staphylococcus epidermidis (MSSE) (ATCC 12228). All strains were provided by Kyungbook National University Hospital and the Korean Federation of Culture Collections, Korean Culture Center of Microorganisms.

\section{Quantitative PCR}

Multiplex PCR was performed in a $20 \mu \mathrm{L}$ volume that contained $10 \mu \mathrm{L}$ of $\mathrm{iQ}^{\mathrm{TM}}$ Supermix (Bio-Rad, Hercules, CA, USA), $125 \mathrm{nM}$ of each primer, $125 \mathrm{nM}$ probes, and $4 \mu \mathrm{L}$ of template. The amplification procedure for the Bio-Rad iQ5 took place at $95^{\circ} \mathrm{C}$ for 5 minutes, followed by 50 cycles at $95^{\circ} \mathrm{C}$ for 10 seconds and $57^{\circ} \mathrm{C}$ for 30 seconds with, fluorescence acquisition after every cycle. The sequence of the TaqMan primers and probes for MRSA qPCR was based on work from Francois et al. ${ }^{17}$ and modified by the Beacon Designer (Premier Biosoft, San Diego, CA, USA) software, as described in Table 2.

Table 1. Sequence of primers and probes for spiked an internal control (SPUD)

\begin{tabular}{|c|c|c|c|}
\hline $\begin{array}{l}\text { Gene and prim } \\
\text { or probe name }\end{array}$ & Sequence $\left(5^{\prime} \rightarrow 3^{\prime}\right)$ & Length & $5^{\prime}$ dye \\
\hline \multicolumn{4}{|l|}{ SPUD } \\
\hline F SPUD & ACGGCAAATAAAGACATAATACATA & 25 & \\
\hline R SPUD & CATCCTTACATGGCACCA & 18 & \\
\hline P SPUD & TCCTAACTTGGCTITAATGGACCTCCA - BHQ1 & 27 & FAM \\
\hline A SPUD & $\begin{array}{l}\text { ACGGCAAATAAAGACATAATACATAAGCATTATCCTAACTTGGCTIAATGGACCTCCAATाTGAGT } \\
\text { GTGCACAAGCTATGGAACACCACGTAAGACATAAAACGGCCACATATGGTGCCATGTAAGGATG }\end{array}$ & 132 & \\
\hline
\end{tabular}

F: forward primer; R: reverse primer; $P$ : probe; A: amplicon. 
SJ Kwon et al: qPCR for etiologic diagnosis of MRSA pneumonia

Table 2. Sequence of primers and probes for the mecA, femA-SA, and femA-SE genes

\begin{tabular}{|c|c|c|c|}
\hline Gene and primer or probe name & Sequence $\left(5^{\prime} \rightarrow 3^{\prime}\right)$ & Length & $5^{\prime}$ dye \\
\hline \multicolumn{4}{|l|}{ mecA } \\
\hline $\mathrm{F}$ mecA & ACGAGTAGATGCTCAATA & 18 & \\
\hline $\mathrm{R}$ mecA & GACGCTATGATCCCAATC & 18 & \\
\hline $\mathrm{P}$ mecA & AACTACGGTAACATTGATCGCAACG - BHQ2 & 25 & CalRed610 \\
\hline \multicolumn{4}{|l|}{ femA-SA } \\
\hline F femA-SA & GGTGCCTITACAGATAGC & 18 & \\
\hline R femASA & TTCCCACTAAATGTGTTCA & 20 & \\
\hline P femA-SA & AGTCATTCACGCAAACTGTTGGC - BHQ1 & 24 & FAM \\
\hline \multicolumn{4}{|l|}{ femA-SE } \\
\hline F femA-SE & TCCGTITGAAGTAGTITAC & 19 & \\
\hline $\mathrm{R}$ femA-SE & TACCGATTAATACCATGTTC & 20 & \\
\hline P femA-SE & AATCATCTTCCATTGAACCGCATAGC - BHQ1 & 26 & YAK \\
\hline
\end{tabular}

F: forward primer; R: reverse primer; $\mathrm{P}$ : probe.

Using this method, detection of only the femA-SA indicated the presence of MSSA, and detection of both the femA-SA and mecA genes indicated the presence of MRSA. If only the femA-SE gene was detected, the presence of MSSE was inferred. Furthermore, the detection of femA-SE and mecA genes, or the detection of the mecA gene alone, indicated the presence of methicillinresistant coagulase negative Staphylococci (MRCNS).

\section{Statistics}

Data are shown as the mean $\pm \mathrm{SD}$. Differences between the two groups were assessed using the student's t-test.

\section{Results}

\section{Result of microbiologic cultures of clinical samples}

The assay was applied to 72 clinical samples of 64 patients from medical $(56.3 \%)$, surgical non-traumatic (15.6\%) and surgical traumatic (28.1\%) categories. Reasons for mechanical ventilation were neurologic diseases $(31.3 \%)$, pulmonary diseases $(29.7 \%)$, postoperative respiratory failure (12.5\%) and the others (26.5\%). The clinical characteristics and the identified species from patients are described and summarized in Table 3.

\section{Measure reproducibility and obtained standard curve about mecA, femA-SA, and femA-SE genes}

We measured the reproducibility of detecting the femA-SA, femA-SE and mecA genes in the reference strains (Table 4).

We obtained the mecA gene standard curves by serial dilution of genomic DNA under the assumption that 1 copy number of the mecA gene corresponds to $1 \mathrm{CFU}^{18}$. The results indicate that the detection limit of the mecA gene is 100 fg:30 copy number (Figure 1).

\section{Comparison between qPCR results and quantit- ative culture results}

We detected MRSA, MSSA, and MRCNS using the qPCR. As a standard curve (Figure 1), we determined the cut-off Ct value (28.94) that corresponded to diagnostic criteria $\left(1 \times 10^{3} \mathrm{CFU} / \mathrm{mL}\right)$ and compared the results of qPCR with results from the quantitative culture. We concluded that the sensitivity and specificity were $94.11 \%$ and $74.54 \%$, respectively (data not shown). Additionally, we chose a quantitative microbiological method based on the inoculation in plates with a 0.001 mL-loop. This method did not allow for a culture of less than $10^{3} \mathrm{CFU} / \mathrm{mL}$.

After discriminating between MRSA cultures and other specimens for determining the presence of pathogens, 
Table 3. Clinical characteristics of study patients

\begin{tabular}{lc}
\multicolumn{1}{c}{ Characteristic } & No. \\
\hline Age, mean \pm SD, yr & $64 \pm 15$ \\
Gender (male/female) & $46 / 18$ \\
APACHE-2 score, mean \pm SD at admission in the ICU & $22 \pm 8$ \\
No. of episodes receiving glycopeptides prior to sampling, \% & $25(34.7)$ \\
Median (IQR) length of glycopeptides, days & $6(3 \sim 7)$ \\
Median (IQR) duration of ICU*, days & $10(7 \sim 18)$ \\
Median (IQR) duration of ICU receiving mechanical-ventilation prior to sampling, days & 8 (6 12) \\
No. of sampling (total) & 72 \\
Bronchoalveolar lavage samples & 21 \\
Bronchial washing samples & 51 \\
No. of detected species (total)*, & 73 \\
Methicillin-resistant Staphylocccus aureus & 16 \\
Methicillin-sensitive Staphylococcus aureus & 1 \\
Methicillin-resistant coagulase negative Staphylococi & 1 \\
Acinetobacter baumannii & 35 \\
Serratia marcescens & 4 \\
Stenotrophomonas maltophilia & 3 \\
Pseudomonas aeruginosa & 3 \\
Achromobacter spp. & 6 \\
Burkholderia cepacia & 2 \\
Candida spp. & 2 \\
Escherichia coli & 2 \\
Penicillin-susceptible Streptococcus pneumoniae & 1 \\
\hline
\end{tabular}

${ }^{*}$ Intensive care unit. ${ }^{\dagger}$ In 1 of 72 samples, 2 species were cultured.

Table 4. Average Ct values for triplicate determinations, with $100 \mathrm{pg}$ of genomic DNA

\begin{tabular}{cccc}
\hline & & Ct values for & \\
\cline { 2 - 4 } Strain & femASA & femASE & mecA \\
\hline MRSA (ATCC33591) & $21.99( \pm 0.16)^{\star}$ & $\mathrm{NA}$ & $20.48( \pm 0.05)$ \\
MSSA (ATCC25923) & $26.54( \pm 0.13)$ & $\mathrm{NA}$ & $\mathrm{NA}$ \\
MSSE (ATCC12228) & $\mathrm{NA}$ & $20.21( \pm 0.11)$ & $\mathrm{NA}$ \\
\hline
\end{tabular}

${ }^{*}$ Average Ct value ( \pm standard deviation).

MRSA: methicillin-resistant Staphylococcus aureus; NA: not assessed; MSSA: methicillin-sensitive Staphylococcus aureus; MSSE, methicillin-sensitive Staphylococcus epidermidis.

we divided the samples into four groups, based on the CFU results from quantitative cultures: group 1 contained samples with culture negatives, group 2 contained samples with cultures of $\geq 10^{3}$ to $<10^{4} \mathrm{CFU} / \mathrm{mL}$, group 3 contained samples with cultures of $\geq 10^{4}$ to $<10^{5} \mathrm{CFU} / \mathrm{mL}$, and group 4 contained samples with a culture of $\geq 10^{5} \mathrm{CFU} / \mathrm{mL}$. The $\mathrm{Ct}$ values were $23.97 \pm$ 3.97 for group 3 and $18.72 \pm 3.06$ in group 4 (Figure 2). The difference between group 3 and group 4 was statistically significant $(p<0.05)$. In the standard curve of the mecA gene, the corresponding $\mathrm{Ct}$ to $\mathrm{CFU}$ values were $2.08 \times 10^{3}$ to $6.05 \times 10^{5} \mathrm{CFU} / \mathrm{mL}$ for group 3 and $1.87 \times 10^{5}$ to $1.65 \times 10^{7} \mathrm{CFU} / \mathrm{mL}$ for group 4 . To minimize the differences between reference MRSA strains and extracted specimens, and to reduce false-positives, we determined that a cut-off value of 27.94 (mean + SD in group 4) corresponded to $1 \times 10^{4} \mathrm{CFU} / \mathrm{mL}$, and a cut-off value of 21.78 (mean $+S D$ in group 2 ) corre- 


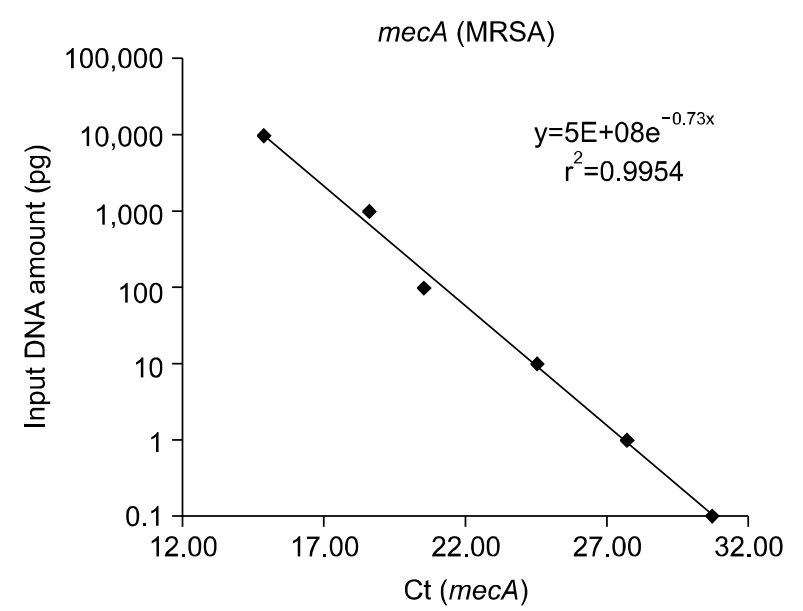

Figure 1. Correlation between input DNA amount and Ct values. MRSA: methicillin-resistant Staphylocccus aureus.

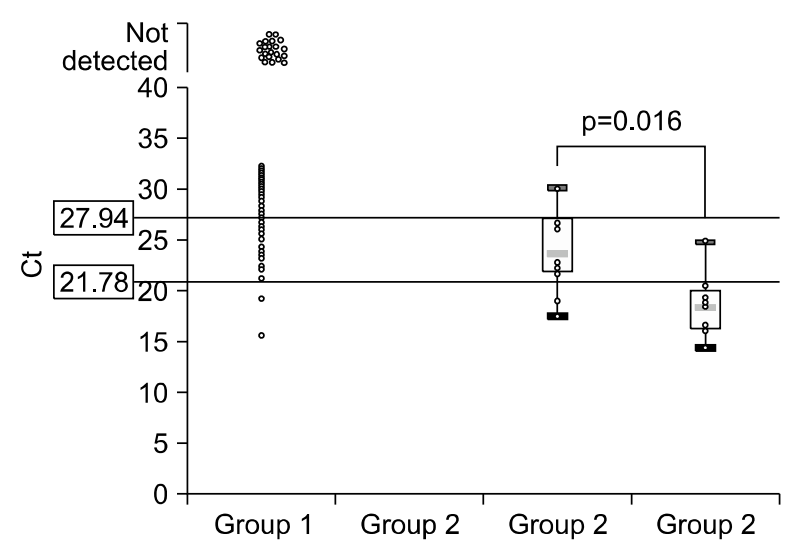

Figure 2. Box-plot of Ct values from methicillin-resistant Staphylocccus aureus (MRSA) cultured specimens. Of the total samples, we created 4 groups based on the colony-forming units (CFU) results from the quantitative culture. Group 1 ( $n=56)$ contained samples with negative cultures, group $2(n=0)$ contained samples with cultures of $\geq 10^{3}$ to $<10^{4} \mathrm{CFU} / \mathrm{mL}$, group $3(\mathrm{n}=8)$ contained samples with cultures of $\geq 10^{4}$ to $<10^{5} \mathrm{CFU} / \mathrm{mL}$, and group $4(n=8)$ had samples with a culture of $\geq 10^{5} \mathrm{CFU} / \mathrm{mL}$. Boxes represent the 25 th to 75 th percentile interquartile range, with the line in the middle representing the median. The upper horizontal line represents the cut-off value of $1 \times 10^{4} \mathrm{CFU} / \mathrm{mL}$, and the lower horizontal line represents the cut-off value of $1 \times 10^{5} \mathrm{CFU} / \mathrm{mL}$.

sponded to $1 \times 10^{5} \mathrm{CFU} / \mathrm{mL}$. To define whether the specimens were pathogens or colonization, we used a cut-off value such that sample $\mathrm{Ct}$ values of $\leq 27.94$ from BAL specimens and $\leq 21.78$ from bronchial wash-
Table 5. Comparison of results by qPCR with quantitative culture $(n=72)$

\begin{tabular}{|c|c|c|}
\hline \multirow[b]{2}{*}{ Quantitative culture result } & \multicolumn{2}{|c|}{ qPCR results } \\
\hline & $\begin{array}{c}\text { MRSA } \\
\text { pathogen }\end{array}$ & $\begin{array}{c}\text { MRSA not } \\
\text { pathogen }\end{array}$ \\
\hline MRSA pathogen $(n=9)$ & 8 & 1 \\
\hline MRSA not pathogen $(n=7)$ & $2^{*}$ & 5 \\
\hline MRSA not cultured $(n=56)^{\ddagger}$ & $5^{\dagger}$ & $51^{\S}$ \\
\hline \multicolumn{3}{|l|}{ Total specimens $(n=72)^{\| \prime}$} \\
\hline Sensitivity & \multicolumn{2}{|c|}{ 8/9 (88.9\%) } \\
\hline Specificity & \multicolumn{2}{|c|}{$56 / 63$ (88.9\%) } \\
\hline
\end{tabular}

In the quantitative culture, the pathogen was evaluated by the diagnostic criteria for BAL specimen $\left(\geq 1 \times 10^{4} \mathrm{CFU} / \mathrm{mL}\right)$ or bronchial washing specimen $\left(\geq 1 \times 10^{5} \mathrm{CFU} / \mathrm{mL}\right)$, according to the materials and methods. The other 2 categories (MRSA, not pathogen and MRSA not cultured) were negative.

${ }^{*}{ }^{\dagger}$ Explained in the Discussion. ${ }^{\dagger}$ Other strains (except MRSA) were cultured. ${ }^{8}$ This results contained the samples of MRSA not detected. "Seventy-two were equal to VAP episode. qPCR: quantitative polymerase chain reaction; MRSA: methicillin-resistant Staphylocccus aureus, BAL: bronchoalveolar lavage; $\mathrm{CFU} / \mathrm{mL}$, number of colony-forming units per $\mathrm{mL}$; VAP: ventilator-associated pneumonia.

ing specimens were diagnosed as pathogens. These cut-off values resulted in a sensitivity of $88.9 \%$ and a specificity of $88.9 \%$ (Table 5). With the exception of the 25 VAP episodes that received antibiotics for MRSA, we analyzed a total of 47 VAP episodes. QPCR assay had a sensitivity of $85.7 \%$ and specificity of $90.0 \%$ for the pre-antibiotic samples. There were 4 false positives and 1 false negative in the qPCR assay.

\section{Discussion}

According to data from the Korean Nosocomial Infection Surveillance System, MRSA is the pathogen most frequently isolated in $\operatorname{VAP}^{19}$. Mortality caused by MRSA pneumonia ranges between $14 \%$ and $47 \%$ but is significantly lower among patients receiving early appropriate antibiotic treatment than in those requiring a change in treatment ${ }^{20}$. Recent studies have correlated qPCR with quantitative culture counts and have provided therapeutic information for applying diagnostic criteria $\left(1 \times 10^{4} \mathrm{CFU} / \mathrm{mL}\right)$ to BAL specimens ${ }^{14}$. To in- 
dicate appropriate therapeutic information, we correlated firstly $\mathrm{QPCR}$ results with clinical pathogens. Therefore, we not only reduced differences between qPCR and quantitative cultures but also suggested a clinical setting for bronchial washing specimens.

We estimated the number of MRSA CFUs isolated from BALs or bronchial washing specimens and compared the results of qPCR with the results of quantitative cultures. In our study, 1 of 72 clinical samples (1.4\%) was classified as a false-negative (Table 5) and this patient may have received inappropriate treatment leading to fatality. The patient's clinical pulmonary infection score (CPIS) was greater than 7 and MRSA grew more than $10^{5} \mathrm{CFU} / \mathrm{mL}$. Combining the CPIS score with qPCR results would likely have yielded a more accurate diagnosis for this patient.

Seven patients' (qPCR, MRSA pathogen and quantitative culture, MRSA not pathogen [2 patients]; qPCR, MRSA pathogen and quantitative culture, MRSA not cultured [5 patients]) (Table 5) results classified as falsepositives. Of the 7 false-positives, five patients' specimens (qPCR, MRSA pathogen and quantitative culture, MRSA not cultured) (Table 5) had no MRSA in a quantitative culture. According to their clinical records, all patients had "clinically-suspected VAP" and CPIS was exceeded 6. Two of the five patients received glycopeptides within the 48 hours prior to obtaining samples. One patient who maintained vancomycin was survived, but the remaining patients with acute respiratory distress syndrome did not respond to teicoplanin. The GPCR method might not distinguish nonviable organisms from viable ones, because the DNA of some nonviable organism could still be extracted ${ }^{21,22}$. We should consider recent antibiotic therapy before extracting the specimens for $\mathrm{qPCR}$, because patients who showed a favorable clinical response to therapy had a rapid fall in colony counts within 24 to 72 hours $^{23}$. One patient with high risk for MRSA pneumonia, whose medication was changed to teicoplanin, showed improvement. Two patients who had not received glycopeptides progressed. Five patients might have had MRSA, so our qPCR method might be more sensitive than a microbiologic culture.

Two patients (qPCR, MRSA pathogen and quantitative culture, MRSA not pathogen) (Table 5) who had clinically-suspected VAP had MRSA that was less than the cut-off value for microbiologically-diagnosed VAP. One patient receiving glycopeptides improved, which suggests that the result of the QPCR were accurate. The other patients' results were false positives. One of seven patients, according to positive results of qPCR (1/72 VAP episodes, $1.4 \%$ ), might have taken unnecessary glycopeptides during our study. In contrast, six of the seven patients with negative or low levels of $\mathrm{CFU} / \mathrm{mL}$ of microbiologic cultures might not have received glycopeptides for MRSA pneumonia, which might have contributed to an unfavorable outcome.

In our study, 51 specimens were bronchial washing samples that were easier to obtain, and the less invasive to critically ill patients, than BAL or protected specimen brush (PSB). The quickest, easiest and least expensive sample to obtain was the endotracheal aspirate. We used, rather than blind sampling, bronchoscopic sampling; blind aspiration sampling could lead to errors and diagnosis could be missed in some patients ${ }^{16}$. Although washing samples were obtained from the distal portion of lobar bronchus and involved VAP, we used a cut-off value established by the endotracheal aspirate diagnostic criteria $\left(\geq 1 \times 10^{5} \mathrm{CFU} / \mathrm{mL}\right)$ instead of BAL ( $\geq$ $1 \times 10^{4} \mathrm{CFU} / \mathrm{mL}$ ), owing to misleading colonization to pathogen by using a low-cut off. In previous studies, when a bacterial count $\geq 1 \times 10^{5} \mathrm{CFU} / \mathrm{mL}$ showed positive culture results of endotracheal aspirate, the sensitivity and specificity were 80\% (range, 60 97\%) and $62 \%$ (range, $41 \sim 74 \%$ ) respectively. There was no difference between the several modalities of sampling in obtaining clinically significant pathogens ${ }^{24,25}$. In addition, the $\mathrm{Ct}$ values of $\mathrm{qPCR}$ were well-correlated with the quantitative culture of specimens. When using the diagnostic criteria of $\leq 27.94$ (equivalent to $1 \times 10^{4}$ $\mathrm{CFU} / \mathrm{mL}$ ) in BAL specimens and $\leq 21.78$ (equivalent to $1 \times 10^{5} \mathrm{CFU} / \mathrm{mL}$ ) in bronchial washing specimens, the sensitivity was $88.9 \%$ and the specificity $88.9 \%$.

The major finding of our study was that the qPCR 
method can be used to confirm whether colonized MRSA is a pathogen involved in VAP. A limitation is that it is difficult to differentiate patients infected only with MRSA from those who are co-infected (MSSA and methicillin-resistant Staphylococcus epidermidis). However, the co-infected patients are clinically uncommon cases.

We used a modified SPUD assay to evaluate experimental and clinical conditions ${ }^{26}$. We spiked the SPUD in the specimen and used a high-throughput column method of DNA extraction. This methodology allows the qPCR method to be utilized routinely. The recovery rate of this method was not constant, as in sample conditions: agglutination of sputum. For this reason, we needed to consider the recovery rate for absolute quantification. With this modification, we were able to consider not only inhibitors but also technical errors. Thus, the process more accurately reflected clinical conditions.

Diagnosis of VAP was very difficult in the ICU patient. Instead of developing a clinical suspected scoring system, diagnostic criteria and microbiology diagnosis were used ${ }^{4}$. Our study shows that the qPCR could be good for diagnosing pneumonia and might be an appropriate substitute for microbiologic cultures. In a study of PSB in suspected VAP, quantitative cultures led to antimicrobial changes in $38 \%$ of the patients with inadequate initial therapeutic plans ${ }^{27}$. In another study, patients with clinically-suspected VAP had a high mortality rate regardless of whether BAL cultures confirmed a clinical diagnosis of $\mathrm{VAP}^{28}$. When adequate antibiotic therapies were initiated very early, the mortality rate was reduced when compared to adequate therapies that were delayed until bronchoscopies were performed or BAL results were known ${ }^{29}$. Rapid turnaround times are therefore highly important in diagnosing and treating VAP. In our study, we not only demonstrated a rapid qPCR method to diagnose whether there were pathogens, but also reduced differences between qPCR and quantitative culture results. In addition, we suggested clinical settings for bronchial washing specimens, which had not yet been established. In conclusion, our results were valuable for diagnosing and identifying pathogens for VAP. We suggest that our modified qPCR is an appropriate and rapid tool for diagnosing clinical pathogens in ICU patients.

\section{Acknowledgements}

This study was supported by Konyang University, Myunggok Research Fund of 2010 (2010-16).

\section{References}

1. National Nosocomial Infections Surveillance (NNIS) system report, data summary from January 1992-April 2000, issued June 2000. Am J Infect Control 2000;28: 429-48.

2. Chastre J, Fagon JY. Ventilator-associated pneumonia. Am J Respir Crit Care Med 2002;165:867-903.

3. Rello J, Ollendorf DA, Oster G, Vera-Llonch M, Bellm L, Redman R, et al. Epidemiology and outcomes of ventilator-associated pneumonia in a large US database. Chest 2002;122:2115-21.

4. American Thoracic Society; Infectious Diseases Society of America. Guidelines for the management of adults with hospital-acquired, ventilator-associated, and healthcare-associated pneumonia. Am J Respir Crit Care Med 2005;171:388-416.

5. Kollef MH, Fraser VJ. Antibiotic resistance in the intensive care unit. Ann Intern Med 2001;134:298-314.

6. Iregui M, Ward S, Sherman G, Fraser VJ, Kollef MH. Clinical importance of delays in the initiation of appropriate antibiotic treatment for ventilator-associated pneumonia. Chest 2002;122:262-8.

7. Katayama Y, Takeuchi F, Ito T, Ma XX, Ui-Mizutani Y, Kobayashi I, et al. Identification in methicillin-susceptible Staphylococcus hominis of an active primordial mobile genetic element for the staphylococcal cassette chromosome mec of methicillin-resistant Staphylococcus aureus. J Bacteriol 2003;185:2711-22.

8. Ruimy R, Dos-Santos M, Raskine L, Bert F, Masson R, Elbaz S, et al. Accuracy and potential usefulness of triplex real-time PCR for improving antibiotic treatment of patients with blood cultures showing clustered gram-positive cocci on direct smears. J Clin Microbiol 2008;46:2045-51.

9. Kilic A, Muldrew KL, Tang YW, Basustaoglu AC. Triplex real-time polymerase chain reaction assay for simultaneous detection of Staphylococcus aureus and 
coagulase-negative staphylococci and determination of methicillin resistance directly from positive blood culture bottles. Diagn Microbiol Infect Dis 2010;66:349-55.

10. Jukes L, Mikhail J, Bome-Mannathoko N, Hadfield SJ, Harris LG, El-Bouri K, et al. Rapid differentiation of Staphylococcus aureus, Staphylococcus epidermidis and other coagulase-negative staphylococci and meticillin susceptibility testing directly from growth-positive blood cultures by multiplex real-time PCR. J Med Microbiol 2010;59(Pt 12):1456-61.

11. Lehmann LE, Alvarez J, Hunfeld KP, Goglio A, Kost GJ, Louie RF, et al. Potential clinical utility of polymerase chain reaction in microbiological testing for sepsis. Crit Care Med 2009;37:3085-90.

12. Reygaert W. Methicillin-resistant Staphylococcus aureus (MRSA): identification and susceptibility testing techniques. Clin Lab Sci 2009;22:120-4.

13. Song JH, Myung SC, Choi SH, Jeon EJ, Kang HG, Lee $\mathrm{HM}$, et al. Multiplex PCR of endotracheal aspirate for the detection of pathogens in ventilator associated pneumonia. Tuberc Respir Dis 2008;64:194-9.

14. Ost DE, Poch D, Fadel A, Wettimuny S, Ginocchio C, Wang XP. Mini-bronchoalveolar lavage quantitative polymerase chain reaction for diagnosis of methicillin-resistant Staphylococcus aureus pneumonia. Crit Care Med 2010;38:1536-41.

15. Wada M, Lkhagvadorj E, Bian L, Wang C, Chiba Y, Nagata S, et al. Quantitative reverse transcription-PCR assay for the rapid detection of methicillin-resistant Staphylococcus aureus. J Appl Microbiol 2010;108:77988.

16. Meduri GU, Chastre J. The standardization of bronchoscopic techniques for ventilator-associated pneumonia. Chest 1992;102(5 Suppl 1):557S-64S.

17. Francois P, Pittet D, Bento M, Pepey B, Vaudaux P, Lew D, et al. Rapid detection of methicillin-resistant Staphylococcus aureus directly from sterile or nonsterile clinical samples by a new molecular assay. J Clin Microbiol 2003;41:254-60.

18. Ho YC, Chang SC, Lin SR, Wang WK. High levels of mecA DNA detected by a quantitative real-time PCR assay are associated with mortality in patients with methicillin-resistant Staphylococcus aureus bacteremia. J Clin Microbiol 2009; 47:1443-51.

19. Kwak YG, Cho YK, Kim JY, Lee SO, Kim HY, Kim YK, et al. Korean nosocomial infections surveillance system, intensive care unit module report: data summary from July 2008 through June 2009 and analysis of 3-year results. Korean J Nosocomial Infect Control 2010;15:14-25.

20. Theaker C, Ormond-Walshe S, Azadian B, Soni N. MRSA in the critically ill. J Hosp Infect 2001;48:98-102.

21. Kashyap B, Kumar S, Sethi GR, Das BC, Saigal SR. Comparison of PCR, culture \& serological tests for the diagnosis of Mycoplasma pneumoniae in community-acquired lower respiratory tract infections in children. Indian J Med Res 2008;128:134-9.

22. Kim NH, Lee JA, Eun BW, Shin SH, Chung EH, Park $\mathrm{KW}$, et al. Comparison of polymerase chain reaction and the indirect particle agglutination antibody test for the diagnosis of Mycoplasma pneumoniae pneumonia in children during two outbreaks. Pediatr Infect Dis J 2007;26:897-903.

23. Garrard CS, A'Court CD. The diagnosis of pneumonia in the critically ill. Chest 1995;108(2 Suppl):17S-25S.

24. Wood AY, Davit AJ 2nd, Ciraulo DL, Arp NW, Richart CM, Maxwell RA, et al. A prospective assessment of diagnostic efficacy of blind protective bronchial brushings compared to bronchoscope-assisted lavage, bronchoscope-directed brushings, and blind endotracheal aspirates in ventilator-associated pneumonia. J Trauma 2003;55:825-34

25. Valencia Arango M, Torres Martí A, Insausti Ordeñana J, Alvarez Lerma F, Carrasco Joaquinet N, Herranz Casado M, et al. Diagnostic value of quantitative cultures of endotracheal aspirate in ventilator-associated pneumonia: a multicenter study. Arch Bronconeumol 2003;39:394-9.

26. Nolan T, Hands RE, Ogunkolade W, Bustin SA. SPUD: a quantitative PCR assay for the detection of inhibitors in nucleic acid preparations. Anal Biochem 2006;351: 308-10.

27. Rodrguez de Castro F, Solé J, Elcuaz R. Quantitative cultures of protected brush specimens and bronchoalveolar lavage in ventilated patients without suspected pneumonia. Am J Respir Crit Care Med 1994; 149(2 Pt 1):320-3.

28. Luna CM, Vujacich P, Niederman MS, Vay C, Gherardi C, Matera J, et al. Impact of BAL data on the therapy and outcome of ventilator-associated pneumonia. Chest 1997;111:676-85.

29. Sanchez-Nieto JM, Torres A, Garcia-Cordoba F, ElEbiary M, Carrillo A, Ruiz J, et al. Impact of invasive and noninvasive quantitative culture sampling on outcome of ventilator-associated pneumonia: a pilot study. Am J Respir Crit Care Med 1998;157:371-6. 